\title{
CLONING AND EXPRESSIONAL ANALYSIS OF STAT1 AND 3 GENES IN ROCK BREAM, OPLEGNATHUS FASCIATUS
}

\author{
Jae-Heon Park ${ }^{1}$, Hyun Do Jeong ${ }^{2}$, Suhee Hong ${ }^{1 \S}$ \\ ${ }^{1}$ Department of Marine Biotechnology, Gangneung-Wonju National University \\ ${ }^{2}$ Department of Aquatic Life Medicine, Pukyong National University
}

\begin{abstract}
Rock bream (Oplegnathus fasciatus) aquaculture in Korea has been threatened by Rock bream iridovirus (RBIV), a megalocytivirus widely infected in various fish species. Major symptoms of RBIV infection is acute inflammation and enlargement of spleen. There is no available vaccine for RBIV though closely related red sea bream iridovirus has been successfully prevented by a commercial vaccine. In our previous study, proinflammatory cytokines and IFN1 gene expression was initially upregulated but later down-regulated by RBIV infection. This study was conducted to clone and analyse the expression of STAT (signal transducers and activators of transcription) 1 and 3. STATs are transcription factors involved in the regulation of immune genes including IFNs and the viral SOCS of megalocytivirus is known to play a key role to inhibit immune response by blocking STAT-JAK pathway. In phylogenetic analysis, rock bream STAT1 and 3 genes were highly homologous with those of mandarin fish, Siniperca chuatsi and yellow croaker, Larimichthys crocea. The expressional study of STAT1 and 3 genes was performed in head kidney upon RBIV infection and immune stimulants like LPS or polyI:C in vitro and in vivo. Head kidney cells were aseptically isolated from rock bream and treated with LPS, polyI:C, or different doses of RBIV and analyzed kinetics of gene expressions of rock bream. STAT1 gene expression was significantly upregulated by polyI:C at $4 \mathrm{~h}$ and sustained at the high expression level until $24 \mathrm{~h}$ while upregulated by RBIV at $4 \mathrm{~h}$ but down-regulated at 24h. Meanwhile, STAT3 gene expression was not significantly affected by polyI:C though STAT3 gene expression was down-regulated at 24h by RBIV. In vivo study showed the down-regulation of STAT3 gene expression at day 4 . Although viral SOCS is known to inhibit the STAT-JAK pathway at the protein level, the downregulation of STAT 1 and 3 gene expressions might be involved in the down-regulation of IFNI and Mx gene expression upon RBIV infection, resulting mass mortality of rock bream.
\end{abstract}

\section{KEYWORDS}

STAT, RBIV, gene expression, Oplegnathus fasciatus 
${ }^{\S}$ Corresponding author. Tel.: +82 33640 2852; Fax: +82 336402955 .

E-mail address: s.hong@gwnu.ac.kr 